\title{
EL PRINCIPIO DE LA CERTEZA \\ EN DESCARTES
}

En la segunda meditación dice Descartes:

Arquimedes, para levantar la tierra y transportarla a otro lugar, pedía solamente un punto de apoyo firme e inmóvil; también tendré yo derecho a concebir grandes esperanzas, si tengo la fortuna de hallar sólo una cosa que sea cierta $e$ indudable.

$\mathrm{Y}$ en $\mathrm{La}$ investigación de la verdad afirma:

De la duda universal, como de un punto fijo e inamovible, quiero derivar el conocimiento de Dios, de mí mismo y de todas las cosas que existen en la naturaleza.

Esa cosa que es cierta e indudable es el cogito que recoge la proposición: "[yo] pienso, [yo] soy, existo", la cual a su vez encierra un principio que denominaré el principio epistemológico fundamental. Este principio está presente en toda la filosofía moderna y contemporánea y, en verdad, puede tomarse como criterio para definir o clasificar las diferentes filosofías. En el presente trabajo elucidaré la forma que dicho principio adquiere en la filosoffa de Descartes y cómo origina perplejidades dado el realismo que finalmente sostiene éste.

\section{LA TEORIA DE LA CERTEZA}

\section{El escéptico filosófico}

El escéptico que Descartes quiere derrotar es un filósofo, es decir, un teórico que duda de lo general y fundamental y no, por ejemplo, de proposiciones particulares o posibilidades concretas de actuar. La tarea de este escéptico se facilita porque - según Descartes - las proposiciones están ordenadas de acuerdo a cierta dependencia, de manera que hay algunas privilegiadas o fundamentales en las que todas las demás descansan; por lo tanto, al dudar de las principales — las que encierran los principios - se habrán puesto en duda todas las demás. Consecuentemente, Descartes se concentrará en las verdades que tienen su origen en los sentidos, las que proceden del estudio de la naturaleza y las que proceden del pensamiento. 
La tesis del escéptico filosófico, según Descartes, consiste en decir que podemos poner en duda todas esas verdades $y$, por consiguiente, podemos considerarlas falsas. ${ }^{1}$ Esto es posible porque puedo pensar que las cosas no son como las percibo, o porque puedo pensar que estoy soñando, o porque puedo pensar en un ser sobrenatural que haga que un triángulo carezca de lados, o que $2+3$ no sumen 5 . La duda más radical es esta última porque en ella se pone en cuestión la validez de la razón. Dicho en otra forma, lo que establezca yo o lo que establezca la raza humana puede ser falso porque yo - la raza humana podemos estar equivocados o confundidos aun cuando creamos lo contrario. No se trata, por lo tanto, de asegurar este $o$ aquel conocimiento, sino de la idea misma de conocimiento.

\section{Interpretación del sentido de las dudas escépticas}

No me interesa ahora discutir los argumentos escépticos ${ }^{2}$ sino ver a través de ellos la tesis del escéptico filosófico que Descartes nos presenta y que desea refutar para siempre. ¿Cuál es esa tesis? Podemos reconstruirla de la siguiente manera: "todo aquello de lo que podemos dudar podemos concebirlo como falso y, por lo tanto, no constituye un conocimiento". Correspondientemente, la tesis positiva diría: "para que algo cuente como conocimiento debe ser inmune a la posibilidad de duda o falsedad".

Según Descartes, el escéptico presenta una demanda coherente: al dudar de los principales tipos de conocimiento, nos pone en el camino de encontrar esa cosa cierta e indudable que permitirá introducir la palabra "conocimiento" y servirá como fundamento o justificación de todo lo que cuente como tal. Sin embargo, aun cuando la duda del escéptico parece solamente epistemológica, Descartes le confiere un alcance mucho mayor, a saber, el de proveer un fundamento metafísico. Dicho de otra manera, la duda del escéptico filosófico no sólo nos obliga a revisar el orden de nuestros conocimientos ${ }^{3}$ a

1 Obsérvese que no necesitan punerse en duda o demostrarse falsas; basta con que se puedan poner en duda. No está en cuestión si Descartes o el escéptico creen que todas las proposiciones son dudables o falsas sino que esto sea posible, es decir, que sea posible considerarlas o concebirlas como falsas. Dice Descartes en la segunda meditación: “...aleján. dome de todo aquello en que pueda imaginar la menor duda, como si supiese que es absolutamente falso..." Sobre la conexión entre conocimiento y duda ver las séptimas objeciones, $2^{2}$ cuestión y nota.

2 Un punto fundamental en el examen de la validez de la duda universal del escéptico filosófico es el que concierne al lenguaje o la significación. El escéptico que introduce Descartes no es tan radical como él desearía desde que no pone en duda el lenguaje o la comprensión de las palabras.

Cfr. las sextas objeciones y la réplica de Descartes.

s Tanto en la carta a Regius, del 24 de mayo de 1640, como en la metáfora de las manzanas que aparece en las séptimas respuestas, Descartes da a entender que su empresa 
manera de encontrar lo que constituye el conocimiento y los conocimientos primarios para luego descubrir el encadenamiento entre éstos y los demás conocimientos, sino que representa una puerta indispensable para poder afirmar que algo existe y para determinar cómo es eso que existe. Más adelante atenderemos la cuestión de determinar el grado de conexión que hay entre el aspecto epistemológico y el metafísico; por ahora, ocupémonos del hecho cierto e indubitable que Descartes busca.

\section{La certeza del "cogito"}

En la segunda meditación Descartes concluye su búsqueda del hecho cierto e indubitable con estas palabras:

No cabe, pues, duda alguna de que yo soy, puesto que me engaña [el genio maligno] $\mathrm{y}$, por mucho que me engañe, nunca conseguirá hacer que yo no sea nada, mientras ya esté pensando que soy algo.

Más adelante, nos aclara que el algo que soy es una cosa que piensa; éste es el hecho indubitable y por lo tanto cierto, que servirá de punto de apoyo para fundar todo nuestro conocimiento del mundo y al mundo mismo también. Examinemos las características de este hecho definitivo y crucial.

Por la forma en que Descartes busca el hecho cierto e indubitable que es el cogito, parece creer que éste constituye una evidencia incontestable que el escéptico debe aceptar. La idea es que al ser consciente del pensa. miento soy consciente de mi existencia y esta conciencia impide la introducción de las dudas escépticas.

Descartes concibe al cogito como algo auto-subsistente e independiente de todas las demás cosas. A la objeción de que para conocer que pienso y existo necesito conocer antes lo que es el pensamiento y lo que es la existencia, Descartes responde que esas nociones son innatas y están en la mente, a disposición del que así piensa.*

consiste solamente en aclarar y ordenar las verdades que conocemos ya y no en introducir un sentido especial de conocimiento (la certeza), ni un conjunto nuevo de verdades.

Su tesis es que hay que partir del núcleo de la certeza y que todo compromiso epistemológion y ontológico debe pasar por el filtro de la certeza. El proceso completo incluye tres etapas, a saber: primero, concebir, por ejemplo, al cogito o a la materia. Luego, determinar lo que incluye esa concepción, esto es, las caracteristicas necesarias de la misma para, en tercer lugar, afirmar si existe.

El punto de partida epistemológico no es renunciable de ninguna manera y constituye su anti-realismo y su innovación metafísica.

4 En las sextas réplicas dice:

Basta con que uno las conozca por medio de ese conocimiento interno que siempre 
Por otra parte, Descartes afirma que la certeza del cogito está limitada en cuanto a su duración. En la segunda meditación declara:

Yo soy, existo, esto es cierto; pero ¿cuánto tiempo? Todo el tiempo que dure mi pensar; pues acaso podría suceder que, si cesase por completo de pensar, cesara al propio tiempo por completo de existir.

La certeza del cogito resulta, por lo tanto, instantánea: sólo cuando se tiene la conciencia de pensar se tiene la conciencia de existir. Si no se tuviese conciencia de pensar, si, por ejemplo, se estuviese inconsciente, no se tendría acceso a la propia existencia y podría ser el caso de que ya no se existiese. Por lo tanto, la afirmación ontológica "(yo) existo" sólo tiene certeza mientras se tiene conciencia de que se piensa."

Sin embargo, la característica más sobresaliente de la certeza del cogito, por lo menos desde el punto de vista epistemológico, es la de su inmediatez. Descartes usa metáforas espaciales para convencernos de que el cogito es cierto. En la segunda meditación declara: "encuentro que el pensamiento es lo único que no puede separarse de mí", y en las réplicas a las segundas objeciones dice: "Por la palabra pensamiento entiendo todo aquello que está en nosotros de tal manera que lo conocemos inmediatamente."

En segundo lugar, la inmediatez produce la inmunidad al error. No es posible ni siquiera dudar de que pienso cuando estoy pensando. En la segunda meditación dice Descartes: "Sin embargo, por lo menos es cierto que me parece que veo la luz, que oigo ruido y que siento calor; esto no puede ser falso, y esto es... pensar." Cuando se le pregunta a Descartes si no se puede dudar también del pensamiento responde diciendo que sólo una persona insana lo haría (a Mersenne, 21 de abril de 1641; a Hyperaspites, agosto de 1641).

Descartes ofrece como razón de inmunidad al error la simplicidad. En las Reglas para la dirección del espiritu (regla VIII) nos dice: "El error solamente puede existir acerca de los objetos compuestos que el entendimiento mismo fabrica." Lo que es simple se capta de una vez y por ello resulta indubitable.

precede al conocimiento reflexivo, y el cual, cuando el objeto es el pensamiento o la existencia, es innato en todos los hombres...

Empero, esta respuesta sólo salva la objeción de que para lograr la certeza del cogito se tenga que abandonar la subjetividad, pero no evade la objeción de que la certeza del cogito no tenga presuposiciones y no sea compleja.

5 Esto queda confirmado por Descartes cuando dice que la garantia divina consiste en conectar los hiatos entre la conciencia necesariamente discreta de las ideas. Cfr. Principios I, 13. Esta tesis es la que servirá de punto de apoyo a Hume en su tarea destructora. 
Simple es nuestra alma y simples son las ideas de figura, número, etc., que Descartes declara inmunes al error. ${ }^{\circ}$

Una tercera característica que atribuye Descartes a la inmediatez del conocimiento consiste en ser no-inferencial. Una y otra vez declara que el cogito no es una inferencia, sino "un acto simple de visión mental..." (Respuestas a las segundas objeciones.)

Una cuarta característica consiste en afirmar que el cogito es auto-verificable porque el ego que afirma "pienso, luego existo" debe convertirlo por ello mismo en verdadero.

Más tarde -en la tercera meditación — Descartes introduce su tesis de la certeza bajo dos criterios aparentes, a saber, el de la claridad y el de la distinción. Asimismo, extiende la tesis de la certeza del cogito a las ideas en general, una de las cuales es el cogito mismo. De ahí en adelante queda establecido que la verdad y la certeza se dicen de las ideas y que cualquier verdad que quiera calificar como certeza debe cumplir con esos dos criterios.

En los Principios de la filosofía establece esos criterios de la siguiente manera:

Llamo clara a aquélla que está presente y manifiesta a la mente atenta, como decimos que vemos claramente las cosas que, presentes al ojo que las mira, lo impresionan con bastante fuerza y claridad. En cambio llamo distinta a la que siendo clara está tan precisamente separada de todas las otras, que no contiene en sí absolutamente nada más que lo que es claro.

La claridad encierra la clave del concepto de inmediatez. Las metáforas espaciales de algo inmediato, presente y manifiesto apuntan a un privilegio epistemológico de estas ideas, a saber, que la distancia entre ellas y la mente es tan escasa que no dan ocasión de error ni de duda y, por lo tanto, poseen certeza. Esta es en parte la razón de que los sentidos no sean aceptados: a saber, que nos dan conocimiento de una realidad externa no auto-contenida y por ello mismo incapaz de certeza. La inmediatez resulta en este sentido un acceso privilegiado.

Pero esta tesis de la claridad también resulta en algo más que Descartes asume, a saber, que las verdades auténticas se le imponen a la mente, es decir,

6 Véase a este respecto lo que dice del conocimiento que nos da la intuición.

En la tercera de sus Reglas - por ejemplo- nos dice: "Por intuición entiendo... la concepción que una mente atenta y despejada nos da tan fácil y distintamente que no queda duda alguna sobre lo conocido."

En las interpretaciones modernas se habla de incorregibilidad, pero esta noción no es adecuada para capturar la certeza cartesiana de cada uno en la que poco o nada tienen que ver los demás. 
que la mente es meramente receptiva ante estas verdades que se le presentan manifiestamente. Así, por ejemplo, en las circunstancias en las que se da la experiencia del cogito, el ego cartesiano no tiene más remedio que aceptar, concebir y creer la verdad del cogito. A esta última característica del cogito podemos denominarla evidente. Esta nota de la evidencia nos servirá más tarde para captar mejor el realismo de Descartes.

\section{CERTEZA, CONOCIMIENTO, VERDAD Y JUICIO}

La certeza consiste, por lo tanto, en tener ideas claras y distintas. En la medida en que nos atengamos a la idea y no excedamos su contenido presente a la conciencia, es decir, en la medida en que no juzguemos o nuestro juicio no desborde el contenido de la idea, en esa medida tendremos no sólo conocimiento sino también certeza. El error, nos dice Descartes una y otra vez, nace de que la voluntad -al juzgar - excede lo que está presente a la conciencia. En la tercera meditación, por ejemplo, dice Descartes:

$\mathrm{Y}$ ahora, en lo que concierne a las ideas, si se consideran solamente en si mismas, sin referirlas a otra cosa, no pueden, hablando con propiedad, ser falsas; pues ora imagine una cabra o una quimera, no es menos cierto que imagino una o la otra... Así, pues, sólo quedan los juicios, en los cuales debo tener mucho cuidado de no errar.

El consejo que repite Descartes a lo largo de la cuarta meditación es que el juicio se limite a lo que la idea presenta en la conciencia; si hago eso no podré equivocarme y habré logrado la verdad. Asi, por ejemplo, concluye en la cuarta meditación:

mientras contengo mi voluntad dentro de los límites de mi conocimiento, sin juzgar más que de aquellas cosas que el entendimiento representa claras y distintas, no puede suceder que me equivoque, porque toda la concepción clara y distinta es, sin duda, algo, y por lo tanto, no puede provenir de la nada... y, por consiguiente, hay que concluir que esa concepción o ese juicio es verdadero.

De acuerdo con Descartes, el juicio es el asentimiento o rechazo del acuerdo o desacuerdo entre dos o más ideas. Pero no está claro si el juicio es el único lugar de la verdad o la falsedad, pues Descartes habla continuamente de ideas que son verdaderas. Pero si hay ideas verdaderas debe haber ideas falsas. $\mathrm{Y}$ asf es: con sorpresa vemos que Descartes afirma que la idea misma puede ser falsa. 
En la tercera meditación y en el coloquio con Burman habla de una falsedad de la idea misma. Así dice en el primer texto:

Pues aun cuando he dicho anteriormente que sólo en los juicios puede darse la verdadera y formal falsedad, sin embargo, puede haber en las ideas cierta falsedad material, a saber: cuando representan lo que no es nada, como si fuera alguna cosa...

Como ejemplos cita el frío y el calor y dice que no son nada porque no sabemos si el frío es ausencia de calor o viceversa y esto demuestra que no son cualidades de las cosas. El cargo es, entonces, que estas ideas no tienen causa en las cosas y no que no representen. En las cuartas objeciones, Arnauld le opone que la idea misma no puede ser falsa y lo acusa, por tanto, de confundir idea con juicio. Dice:

es tu juicio el que es falso, si juzgas que es la idea de frío; pero ella misma es en sí lo más verdadero. Similarmente, la idea de Dios no debe calificarse como materialmente falsa aun cuando algunos, como los idólatras, la transfieran a algo que no es Dios.

Sin embargo, Arnauld parece endosar la tesis de que la idea es verdadera cuando lo que debe decir es que es idea (representación) o no lo es y que sólo el juicio es verdadero o falso.

En verdad, Descartes habla continuamente como si hubiese ideas o actos simples de aprehensión o concepción que son intrinsecamente verdaderos y que no pueden ser falsos. Sin embargo, si no es posible aplicarles el predicado de falsos pareciera que lo que debemos concluir es que tampoco pueden ser verdaderos; que no se suscita respecto de ellos la cuestión de la verdad y la falsedad y, por lo tanto, que Descartes no puede apoyarse en ellos para responder al escéptico. Con esta objeción en mente examinemos la respuesta de Descartes y veamos si la verdad fundamental del cogito no encierra un error igualmente fundamental.

En respuesta a Arnauld, Descartes recurre a la distinción entre la idea como duplicado o representación de algo y la idea en sí misma, sin referencia a ninguna otra cosa $o$ ente. Dice entonces que verdad o falsedad se dicen de la idea en el primer sentido, pero no en el segundo, y por ello hay que introducir otro sentido para conceptuar la falla que puede tener la idea misma: esto es lo que quiere decir con "falsedad material" de la idea. Pero es justamente entonces cuando la sugerencia de Arnauld cobra sentido, pues ¿por qué no hablar del fracaso de la idea, en tanto representación, como de un error de juicio, y distinguirlo así del fracaso en la idea misma? Esta distinción es similar a la que se da entre nombrar y predicar: la predicación es la 
que se califica como verdadera o falsa, no los nombres. El nombre puede fracasar o tener éxito, pero no puede ser verdadero ni falso. Cuando el nombre fracasa decimos simplemente que no hubo nombre o que no se nombró.

Pero el motivo de la disputa entre Descartes y Arnauld es más grave; concierne, a saber, a la teoría de la certeza de aquél. Para darnos cuenta de esto revisemos de nuevo la imagen de la verdad que encierran los putativos criterios de la claridad y la distinción.

Descartes asegura una y otra vez que si contenemos el juicio no caeremos en el error y estaremos a salvo del escéptico. ¿Cómo entender esta contención? Unas veces Descartes parece decirnos que hay que evitar juzgar, y simplemente contemplar lo que aparece a la conciencia. Esto puede hacerse de dos maneras: porque no se haga juicio alguno y se permanezca en silencio, o porque se expresen las creencias en una forma neutral, como recomienda en la segunda meditación. ${ }^{7}$ En ambos casos, puesto que ex-hypothesi no hay juicio, no habrá verdad y, por lo tanto, la certeza así lograda resultará irrelevante para el escéptico.

Sin embargo, en otras ocasiones Descartes dice que sf hay que juzgar, pero limitando el juicio a la experiencia presente a la conciencia. Esto también puede lograrse de dos maneras: primera, porque el juicio sólo informe del contenido presente a la conciencia, por ejemplo, de que hay un dolor o una sensación de dolor; segunda, porque no se lo refiera a nada externo a la conciencia.

El primer camino se asemeja mucho a los casos considerados antes y sólo se diferencia porque sí se emplea el lenguaje para hacer una afirmación expresa, algo así como "es verdad que (me) duele" en vez de decir "(me) duele". La afirmación de estos contenidos mentales serfa la única base desde la cual habria que reconstruir el mundo material y las personas para poder responderle al escéptico, y lo menos que puede decirse es que la tarea por cumplir es demasiado grande. ${ }^{\mathrm{s}}$

7 Esta tesis aparece a lo largo de la cuarta meditación y en los Principios de la filosofia, parte I, XLII al XLVI. La doctrina alli expuesta es que sólo debemos ser conscientes de, por ejemplo, el dolor que sentimos sin juzgar nada cerca de él. Pero, si es así, sólo estaremos atendiendo al dolor y no se suscita la cuestión de la verdad y la falsedad.

En la segunda meditación, en cambio, recomienda que neutralicemos el juicio con la expresión "me parece que..." a manera de evitar la aserción; en este caso tampoco habrá cuestion de verdad o falsedad.

Dicho de otra forma, aunque se quiera hablar en esos casos de verdad o falsedad, esa "verdad" es irrelevante para responder a las dudas del escéptico, pues lo que el escéptico filosofico cuestiona no son esas experiencias o datos de la conciencia sino las verdades -que se dan a nivel judicativo - acerca del mundo y las personas. A menos que Descartes pueda reducir esas verdades sustanciales a los contenidos mentales, no habrá respondido al escéptico.

8 Hay que pensar, sobre todo, en verdades sustanciales acerca del mundo y las perso- 
La segunda vía - no excluyente de la anterior- es la del subjetivismo, y resulta una salida fatal, pues exige que no haya pronunciamientos acerca (de la naturaleza) del mundo y las personas. La idea es que, para esquivar al escéptico, hay que retrotraerse a los pensamientos propios y renunciar a hablar del mundo y las personas. Esta extraña via hacia la certeza tiene un precio absurdo. Encierra el "problema" de tener que "salir" de la conciencia o de la subjetividad para alcanzar el mundo. ${ }^{9}$

La situación a la que hemos llegado, por lo tanto, es la siguiente: Descartes sólo puede retener las exigencias de la certeza retrotrayéndose a su subjetividad y comprometiendo la distinción concepción-juicio. ${ }^{10}$ Esto parecerfa comprometerlo a un anti-realismo extremo e incluso a un idealismo -y la historia filosófica, acertadamente, le confiere la paternidad de este último. Empero, las cosas no son tan claras en Descartes mismo. En lo que sigue me dirigiré a aclarar la relación que hay entre el principio epistemológico fundamental y la idea esencialista de una única realidad que es causalmente responsable de las ideas y del conocimiento.

Antes, sin embargo, introduciré otro elemento de perplejidad, a saber, la teoria de la significación de Descartes.

\section{CERTEZA Y SIGNIFICACIONN}

Hasta ahora hemos hablado de conocimiento de manera que el cogito parece darnos sólo un principio del conocimiento de la realidad. Sin embargo, el

nas. El cogito, por ejemplo, no resuelve la duda del escéptico porque sólo expresa una condición general del conocimiento y no nos ofrece una teoría verdadera acerca de la persona. Tampoco el dolor cartesiano nos da una teoría verdadera acerca de ese estado mental. Cfr. mi artfculo "El dualismo sustancial de Renato Descartes", Didnoia 1977, donde explico lo que Descartes entiende por dolor.

- Todos estos problemas espúreos constituyen buena parte de la temática de la filo. sofia francesa a partir de los años cincuentas, problemas concebidos en plena ceguera de la obra de Wittgenstein. Véase, por ejemplo, el tratamiento de la tesis solipsista en el Tractatus Logico-Philosophicus.

Sobre la radical equivocación que supone esta vía hacia la certeza, véase On Certainty de Wittgenstein, B. Blackwell 1969 (hay traducción en Editorial Tiempo Nuevo, Venezuela, 1972). En esa obra Wittgenstein explora otra estrategia frente al esœeptico cartesiano; sobre esto véase mi nota "De la duda, el escepticismo, el conocimiento y la certeza" en Nexos, marzo 1978, número 3.

10 La dificultad de esta concepción puede apreciarse mejor si se observa la similaridad entre esta tesis del conocimiento cierto que exige un objeto permanentemente presente $y$ la tesis del nombre propio lógico según la cual un signo serfa un nombre, sólo si siempre va acompañado por su objeto. La inutilidad de tales nombres basta para descalificar una teorfa tal. Si el conocimiento no excediera la presencia de los objetos conocidos no tendria la utilidad que tiene en nuestro sistema conceptual. En este sentido, el conocimiento rebasa la mera concepción y queda del lado del juicio. 
principio de certeza que subyace al cogito es mucho más ambicioso y se aplica también al lenguaje. Lo que el principio exige es que todo conocimiento tenga como correlato ideas y, concomitantemente, que toda comprensión del lenguaje consista en tener ideas. El tener ideas resulta, por lo tanto, una condición necesaria y suficiente de poder entender un signo. ${ }^{11}$

Ahora bien, dada la tesis de la inmediatez, la presencia de la idea es garantia completa de la comprensión del signo, y esto quiere decir que, desde el punto de vista de la teoría de la significación, Descartes es un realista. La presencia de la idea es lo que confiere significatividad al signo. ${ }^{12}$

De ser esto así, tendríamos una situación que se antoja paradojica; a saber: Descartes sería realista en su teoría de la significación y anti-realista en su teorfa del mundo, a menos que su teorfa de las ideas no implique una postura anti-realista. Tratemos entonces de determinar la fuerza y el carácter de su teoría de las ideas.

\section{CERTEZA Y EXISTENCIA}

La razón más poderosa para alinear a Descartes con los anti-realistas es su teoría de las ideas. El argumento del cogito pretende sentar el principio metafísico según el cual, todo ente debe ser aceptado porque la conciencia lo muestra con certeza. Según Descartes, nuestra propia alma pasa esta prueba en el cogito y por ello queda aceptada.

Pero entonces parecería que la certeza impone un control sobre los entes, una especie de control verificacionista de acuerdo con el cual, para que podamos aceptar un ente, deben cumplirse previamente ciertas condiciones epistemológicas. En verdad, hay ciertos pasajes en los escritos de Descartes que invitan a esta interpretación. Particularmente, está la carta a Clerselier del 12 de enero de 1646. Ahí leemos:

De aquí que el error más absurdo y extravagante que un filósofo pueda cometer es el querer hacer juicios que no tengan relación con sus percepciones de las cosas.

Hay un control general que vuelve inteligible el lenguaje, y que no consiste

11 En mi artículo "Acerca de la tesis filosófica del pensamiento en relación con la tesis del lenguaje de Renato Descartes" Diánoia, Fondo de Cultura Económica, 1976, analicé la teoría del lenguaje de Descartes desde la perspectiva de su tesis del pensamiento e implicitamente de su tesis de la certeza.

12 Curiosamente, también la presencia de la idea es la que hace verdadero al signo o al conjunto de signos. Esta conflación del significado con la verdad constituye una forma del error verificacionista y es una consecuencia del realismo interno o subjetivo que defiende Descartes. 
en las cosas mismas sino en las percepciones de esas cosas. El tinte anti-realista está ahí. Pero esa imagen aparece de modo más general y contundente en el siguiente pasaje de la misma carta:

El pensamiento [la idea clara y distinta] de cada persona, i.e. la percepción o el conocimiento que tiene de una cosa, debe ser para ella la regla de la verdad de esa cosa; es decir, que todos los juicios que haga deben conformarse con esa percepción para ser correctos.

Ésta es la reconstrucción racionalista del mundo a la que Descartes nos invita. El principio de la certeza se torna compatible con la visión racionalista y a la vez con el control del pensamiento sobre los entes. La verdad no va sin más con la realidad; por el contrario, requiere la comprobación por medio del pensamiento. Sin embargo, aquí todavía no se acepta el anti-realismo, y mucho menos una postura de tipo fenomenalista, porque todavía no tenemos una teoría anti-realista del pensamiento o de la idea.

La declaración cuasi-ideológica de su propósito queda expresada en este otro parágrafo de la misma carta, donde dice:

Pues si las cosas que concebimos deben considerarse falsas solamente porque las concebimos, sólo nos queda aceptar como verdaderas las cosas que no concebimos y sacar nuestro sistema de creencias fuera de lo que concebimos, imitando a otros sin saber por qué lo hacemos y profiriendo tan sólo aquellas palabras que no podemos entender, como las cotorras.

La comprensión o el entendimiento deben quedar ligados a la conciencia so pena de volverse ininteligibles. Una creencia no concebida es una contradicción en los términos, asf haya un ente que le corresponda. Otra vez aparece la tentación anti-realista, pero otra vez surge una reserva crucial, a saber: todo depende de la interpretación que demos a esa concepción o idea; ¿qué tipo de interpretación debemos darle entonces?

En la primera meditación dice Descartes:

He juzgado que era preciso acometer seriamente, una vez en mi vida, la empresa de deshacerme de todas las opiniones a las que había dado crédito, y empezar de nuevo, desde los fundamentos, si quería establecer algo firme y constante en las ciencias.

¿Por qué pensó Descartes que los sistemas metafísicos clásicos y medievales eran tan insatisfactorios que exigfan un comienzo radical? $¿ Y$ debemos interpretar este retorno radical como un rechazo del realismo? La cosa cierta e indubitable que busca Descartes y que da origen al principio de la certeza, 
¿exige también una postura anti-realista y aún idealista? De no ser así, ¿cuál es la situación conceptual? A reserva de ampliar posteriormente lo que sigue, diré esquemáticamente algunas cosas.

Una buena manera de aproximarnos a la dificultad fundamental consiste en preguntarnos si Descartes está comprometido con una tarea o programa de fundamentación -independientemente de si intentó o no llevarlo a cabo. Parecería que sí está obligado, puesto que el principio de la certeza lo ha dejado con el ego y las ideas, y puesto que desea afirmar la existencia de las cosas independientemente de su ego, debemos concluir que busca una conexión o relación adecuada entre sus ideas y los objetos extra-mentales.

Sin embargo, Descartes ni siquiera se plantea una tarea tal. En lugar de ello introduce la existencia de Dios y la garantía - vía su carácter de ser verísimo- de que las ideas que tenemos están causadas por los cuerpos a los cuales se asemejan o de los cuales son réplicas. La garantía divina es una garantía en favor uel realismo y el Dios de Descartes es un Dios que se inclina en favor del realismo. Dicho en otra forma: lo que Dios garantiza es que las ideas claras y distintas reflejen o reproduzcan las cosas tal como éstas son. Las ideas pierden, por lo tanto, su carácter de tercera realidad. Dada la garantía divina, se restablece la dualidad mente-cosas y también la verdad como correspondencia entre la mente y las cosas.

Esta interpretación refuerza la respuesta de Descartes a las primeras objeciones de Caterus. Éste le reprocha que la idea no es una realidad sino parte de la mente misma. Descartes le responde así:

El objeto exterior no está en el entendimiento; pero hay en éste una realidad representativa de aquél, llamada realidad objetiva de la idea. Concedo que la realidad objetiva no es un ser real, en cuanto no está fuera del entendimiento; ...pero si algo real que es concebido; luego esta concepción necesita una causa...

Esta respuesta asienta el esquema de Descartes, según el cual hay una realidad que causa las ideas y a través de éstas llega a la mente. El análisis de la idea resulta, así, paradójico, pues por una parte la idea es un ente y, por la otra, dicho ente -dada la garantía divina- es transparente y sólo refleja la realidad misma. En suma, la proposición que expresa el cogito no es verdadera porque haya una idea sino porque hay un alma que le corresponde. El realismo es definitivo.

¿Pero qué sucede entonces con las ideas que provienen de los sentidos? ¿Qué sucede con los casos de ilusión, alucinación y demás? Aquí la incoherencia amenaza a Descartes, quien busca expedientes para deshacerse de estos casos. Algunas veces recurre a su teorfa del juicio y otras a nuestra finitud para exonerar a su Dios. Pero detrás del rechazo de las ideas adventicias 
como fuentes de conocimiento, está su fe racionalista - no sin argumentosy la correlativa restricción al principio de la certeza, a saber, que sólo hay verdad en el caso de ciertas propiedades.

Esta primera restricción al principio de la certeza hace cuestionable la introducción de la garantía divina, pues si hay algunas ideas que no representan o que falsean la representación, Descartes nos debe una explicación de cómo funciona dicha garantía. Dios pudo garantizar las ideas sensoriales y privar de garantía a las ideas matemáticas y de número. ¿Por qué no procede así $y$, en general, cuál es la regla que rige su proceder? El problema con la garantía divina -o diabólica, para el caso- es que no sabemos de ella porque no podemos saber de la esencia divina y de sus acciones. Sabemos que la garantía va en favor de un realismo fuerte, pero no sabemos cómo garantiza ese realismo. Es decir, por ejemplo, cómo ese realismo elimina todo fenomenalismo o idealismo y cómo excluye las ideas sensoriales y así en lo demás.

Pero ¿qué tan dañina es, de hecho, la posición de Descartes? Es decir, ¿qué tan reaccionario es el principio epistemológico fundamental? Descartes lo maneja con lasitud suficiente como para que puedan admitirse las entidades de la metafísica especial, a saber, el alma, el mundo y Dios. La clave de esta lasitud es su teoría del pensamiento, que es mucho más amplio que la sensibilidad, la imaginación o la memoria. El pensamiento puede comprobar todo lo inteligible y las entidades metafísicas son per definitionem inteligibles. Esto salva a Descartes de las acusaciones de que su principio es demasiado restrictivo, pero lo hunde en la acusación de que para deshacerse de los prejuicios, hipóstasis y demás tiene que recurrir exclusivamente a su verificación interior, esto es, a rechazar o aceptar que la idea en cuestión sea clara u oscura, y esto, lejos de proveer una razón, demanda un sinnúmero de ellas para que sea creíble, pero sobre todo para que no resulte arbitraria.

Asf́ llegamos a una evaluación final del principio de la certeza de Descartes. El principio incluye un movimiento doble: subjetivismo y realismo. El primero empuja en la dirección del idealismo pero la garantía divina lo neutraliza e inclina la balanza hacia el realismo. Si se suprime la garantía divina ya no habrá posibilidad de realismo y la tesis de las ideas llevará irremediablemente a algún tipo de idealismo y al consecuente programa reduccionista o fundamentalista. ${ }^{13}$

Dicho en otra forma, creo que el principio epistemológico fundamental o principio de la certeza tiene naturalmente un carácter idealista que Locke y Berkeley van a desarrollar, pero en Descartes este carácter idealista queda

13 Este es el motivo de las teorías neo-cartesianas como la teoria de la constitución de Husserl (véanse sus Ideas) y de las avezadas construcciones de B. Russell (véase Our Knowledge of the External World). 
neutralizado por la introducción de Dios. ${ }^{14} \mathrm{E}$ idealismo está ahí, potencialmente, en el principio de la certeza; pero en la filosofía de Descartes no aparece, o queda neutralizada, esa posibilidad anti-realista del principio.

Instituto de Investigaciones Filosóficas

ENRTQue Villanueva

Untversidad Nacional Autónoma de México

14 La garantía divina opera en forma irrestricta. En la cuarta meditación dice:

pues toda percepción clara y distinta es sin duda algo y por lo tanto no puede venir de la nada sino que debe tener necesariamente a Dios como su autor - a Dios quien, siendo supremamente perfecto, no puede ser la causa de ningún error y consecuen. temente debemos concluir que tal percepción debe ser verdadera.

Descartes pretende que Dios garantiza todos los datos inmediatos de nuestra conciencia. A Hobbes le replica, sin embargo, que se puede tener conocimiento pero no certeza sin Dios. De cualquier manera, la introducción de Dios libera a Descartes de caer en la incoherencia pero sólo al precio de la oscuridad o el silencio, o lo que es lo mismo, de la noteoría y la no-explicación.

El argumento se puede expresar asi: el principio causal, introducido en la tercera meditación, de acuerdo con el cual las ideas claras y distintas deben tener necesariamente un objeto que es su causa, no ha pasado por el colador de la certeza y resulta vulnerable al ataque del escéptico. Si se apela a Dios para garantizar su certeza se habrá caído en un círculo vicioso; pues la idea de Dios es ella misma una idea clara y distinta.

No sólo es infiel Descartes al principio epistemológico fundamental, sino que el sentido de esta infidelidad cancela todo el empuje anti-realista de su filosofia; también en este sentido resulta Descartes solamente un precursor de la filosofía moderna. 